\title{
An Investigation of Using a Tablet Computer for Searching on the Web and the Influence of Cognitive Load
}

\author{
Nicolas Debue ${ }^{\mathrm{a} \otimes}$, Nora Oufi ${ }^{\mathrm{a}} \&$ Cécile van de Leemput ${ }^{\mathrm{a}}$ \\ ${ }^{a}$ Université libre de Bruxelles, Research Center for Work and Consumer Psychology
}

\begin{abstract}
This paper presents two lab-based experiments that compare laptop and tablet performance in web-based search. Compared to laptops, tablets feature smaller screens and require gestures to interact with them and to input information. It is thought that tablets may require the use of additional mental resources and that this demand may hinder performance. A first experiment $(\mathrm{N}=69)$ found that laptop users outperformed tablet users while conducting assigned information search tasks on Wikipedia, and a second experiment $(\mathrm{N}=60)$ replicated these results. In the second study, subjective ratings of cognitive load and eye-tracking data were collected to explore the impact of tablet use on intrinsic and extraneous load. The data collected indicated that the decrease in performance is related to an increase of extraneous load when using tablet computers. Hence, policy makers should be cautious when considering whether to replace laptops with tablets in the classrooms.
\end{abstract}

Keywords $\backsim$ Tablet computer, performance, information search, cognitive load theory. Tools $₫$ R.

\author{
Acting Editors \\ Julie Albentosa (In- \\ stitut de Recherche \\ Biomédicale des \\ Armées) \\ - Lucile Chanquoy \\ (Université Côte \\ d'Azur, CNRS, BCL, \\ France) \\ Reviewers \\ - Three anonymous \\ reviewers
}

\section{ndebue@ulb.ac.be}

10.20982/tqmp.16.3.p226

\section{Introduction}

The year 2015 saw a shift in the world of information technology industry with the number of tablet computers sold being greater than the total sum of both desktop computers and laptops (IDC, 2016). From playing games at home to presenting slideshows at work, tablet computers are used for a variety of purposes and in a wide range of contexts (M"uller, Gove, Webb, \& Cheang, 2015). In the US education system, tablet computers are still proliferating in all grades with a growing number of students using mobile devices at schools, with up to $39 \%$ of students in grade K-2 having access to school provided tablet computers (Project Tomorrow, 2017).

This trend is similar in other countries and is supported by growing enthusiasm among education specialists, teachers and students. It is felt that tablet computers could be a "game changer" in education, by offering a range of new applications specifically dedicated to learning. Numerous studies have focused on the impact of the tablet computer in education claiming that, in general, tablet computers support learning and educational goals. In their critical review, Haßler, Major, and Hennessy
(2016) concluded that the use of tablets supported positive learning performance in 16 out of 23 studies. Also, tablet computers have been reported to increase student motivation (Sachs \& Bull, 2012) and performance (Churchill, Fox, \& King, 2012; Chou \& Feng, 2019) in learning. Tablets also facilitate reading (Fernández-Lopez, Rodriguez-Fórtiz, Rodríguez-Almendros, \& Martínez-Segura, 2013) and annotating documents by reducing the split-attention effect (Ando \& Ueno, 2011). Students are more likely to engage in the learning activity as well as communicate and collaborate with their peers and teachers when using tablet computers (Henderson, Shinkareva, Wang, Luke, \& Olejarczyk, 2013; Mercier, Higgins, \& Joyce-Gibbons, 2016). However, some studies have mentioned that the use of tablet computers could be detrimental to learning by disturbing students during the class (e.g. Churchill et al., 2012).

In spite of a growing body of research devoted to this topic, it seems that most of those studies suffer from a lack of scientific evidence. Reviewing 359 academic publications about the impact of tablet computers in education, Karsenti and Fievez (2013) concluded that, while the benefits of tablet computers are frequently cited in research, there is not much empirical support provided for these 
claims. This is in line with Percival and Claydon (2015) and Nguyen, Barton, and Nguyen (2015) who pointed out that this body of research is mainly based on descriptive studies and lacks evidence-based research. Furthermore, Mulet, van de Leemput, and Amadieu (2019) identified in their critical literature review that most studies were not explicitly based on theoretical models, especially for those using qualitative methods, which mostly consisted of descriptive analyses or explorative investigations.

Although huge benefits were expected from introducing tablet computers into the classrooms, it turned out that the resulting outcomes did not meet every expectation. The fact that some schools have been turning back, replacing their tablet computers with laptops (Murphy, 2014; Reisinger, 2016), raises many issues with regard to the suitability of this new technology in educational settings. Tablets may not be the proper tool for every type of activity performed at school and may be considered as an enhancement device rather than a replacement for desktop or laptop computers. According to the Project Tomorrow survey (2017), students think that laptops and tablet computers are suited for different types of tasks, regardless of their familiarity with the devices. Both tablet computer and laptop users identified the laptop as the best device to write a report on or for performing online search. Nevertheless, those who had been assigned with tablet computers at school identified tablet computers as best suited for taking notes, watching videos and reading online books, whereas laptop users considered the laptop as the best choice to perform these tasks. In another survey (Kaur, 2013), tablet computers are reported by college students to be mainly used for downloading educational apps, checking e-mails and seeking information on the web.

\section{Web-based information search process}

It is worth noting that performing online search is described as one of the most frequently performed tasks on tablet computers even though both laptops and tablet computers users prefer using a laptop to search online. Despite the growing importance of tablet computers in education, there remains a paucity of evidence on the impact of tablet computers on online-information search performance. The present research seeks to obtain data which help to address this research gap.

Numerous models have described the information search process. Building on Marchioni's model (Marchionini, 1995), Sharit et al. (Sharit, Hernández, Czaja, \& Pirolli, 2008) describe the information search as a multi-stage problem solving process "whereby the problem-solver's knowledge and other mental representations are manipulated to achieve a goal" (Sharit et al., 2008, p, 3). First, the seekers identify the problem and define the goals and subgoals of the search. Second, they generate search terms and keywords that are translated into queries in a search engine. Third, they look over the results and visit the webpages that are relevant with regard to the goals. The search ends when the seekers consider that the goals are reached or when they abandon the search. This is a highly iterative process, since the problem definition and the goals can be modified during the search, resulting in a reformulation of the problem and the related queries. This model emphasizes the important role of the user's prior knowledge and working memory capacity in the assessment of website relevance and the relevance of the information retrieved. Throughout the process, users must keep the goal of the search in working memory while generating queries, selecting webpages and retrieving relevant content. Therefore, both the amount of information that has to be maintained in working memory and the remaining resources available to handle the task can impact the performance in the information search (Sharit et al., 2008). Given that, as mental resources play an important role in keeping the seekers oriented in the search, it is necessary to address the impact of using a tablet computer on the users' mental resources.

\section{Impacts of tablet computer features on the user behav- ior}

To date, a number of studies have investigated the effects of using a tablet computer on user behavior without achieving general agreement. As tablet computers usually feature screens ranging from 7 to 10 inches, they have been reported to dramatically increase scrolling while reading (Sanchez \& Goolsbee, 2010), thereby lowering text comprehension (Sanchez \& Wiley, 2009) and task efficiency (Botella, Moreno, \& Peñalver, 2014). On the other hand, some authors argue that tablet computers foster learning by offering a gesture-based interaction mode that is less demanding in terms of mental resources (Ostrowski, 2014), as it avoids the split attention effect due to the concomitant use of a physical mouse and keyboard (Wang \& Shen, 2012). Reviewing research on using iPads in higher education, Nguyen et al. (2015) concluded that using tablet computers at school is not beneficial to learning. Onscreen keyboard, another key feature of the tablet computer, may hinder users' satisfaction and performance (Chaparo, Nguyen, Phan, Smith, \& Teves, 2010; Findlater \& Wobbrock, 2012; Varcholik, LaViola, \& Hughes, 2012). Varcholik and colleagues (2012) demonstrated that using a virtual keyboard to encode text decreases the speed and increases typing errors, when compared to physical keyboards (laptop or desktop). Moreover, participants reported being less satisfied when using the onscreen keyboard. Users have to devote more attention to the onscreen keyboard when they 
Table 1 - Description of the tasks, goals and actions required to perform the tasks

\begin{tabular}{|c|c|c|c|}
\hline Task & Instructions & Gestures required & Goal of the task \\
\hline 1 & Go to Wikipedia homepage & Left click & Locate a page \\
\hline 2 & Find the section about Anthropology of nutrition & Left click & Locate a section \\
\hline 3 & Find the section about Human nutrition & Left click & Locate a section \\
\hline 4 & Find two taboo practices in primitive cultures & Left click, typing & $\begin{array}{l}\text { Locate pieces of infor- } \\
\text { mation }\end{array}$ \\
\hline 5 & Find the name of the island with oldest people & Left click, typing & $\begin{array}{l}\text { Locate piece of infor- } \\
\text { mation }\end{array}$ \\
\hline 6 & Count the number of elements on can Dyck's artwork & $\begin{array}{l}\text { Left click, zooming in } \\
\text { and out }\end{array}$ & $\begin{array}{l}\text { Count elements in a } \\
\text { picture }\end{array}$ \\
\hline 7 & Find the name of the Slavic goddess of food & Left click, typing & $\begin{array}{l}\text { Locate a piece of in- } \\
\text { formation }\end{array}$ \\
\hline 8 & $\begin{array}{l}\text { Copy the name of the first reference on the page about } \\
\text { Human nutrition }\end{array}$ & $\begin{array}{l}\text { Left click, right click, } \\
\text { copy pasting }\end{array}$ & Copy a piece of text \\
\hline 9 & $\begin{array}{l}\text { Open up the page on } 5 \text { different languages in different } \\
\text { tabs }\end{array}$ & Left click, right click & $\begin{array}{l}\text { Switch between dif- } \\
\text { ferent tabs }\end{array}$ \\
\hline
\end{tabular}

want to reduce their error rate (Findlater \& Wobbrock, 2012). In view of all that has been mentioned so far, one may suppose that tablet computers increase the demand upon users' mental resources. Given that resources available in working memory play a determinant role in the information search process, it is assumed that they negatively impact user's performance.

The aim of this present research is to assess the impact of the device on efficacy and efficiency when performing online search tasks.

The research question is: Does tablet computer negatively impact performance in online search compared to laptop? A first exploratory lab-based study was conducted to address this research question. The method and results are presented and discussed in the next section.

\section{Experiment 1}

\section{Methods}

a) Sample. Sixty-nine undergraduate students from a major Belgian university participated in this study (61 females, 8 males, $M=19.9, S D=2.1$ ). They were all enrolled in an introductory psychology course and get credits for taking part in the experiment. Participants were randomly assigned to one of the two conditions of our study, laptop use $(N=35)$ or tablet computer use $(N=34)$.

b) Control variables. Numerous studies have indicated that previous knowledge of the internet, experience with search engines and familiarity with the device, can all impact the efficacy of the search process (Kellar, Watters, \& Shepherd, 2007; Thatcher, 2008). Familiarity with the devices was controlled by asking the participants to report the number of hours spent on each device on a weekly ba- sis (for laptop and tablet computer).

Familiarity with gestures was also controlled using a 7point Likert scale including 7 items ( $\alpha=.742)$ such as "Using gestures on a tactile device is not a problem for me", "I am familiar with the main gestures used to interact with a tactile device"; "I do not know how to interact with a tactile device”. Independent samples t-tests performed on age, gender or familiarity with the devices and gestures did not yield any significant difference across experimental conditions.

c) Information search tasks. Participants were asked to seek information on the online encyclopedia "Wikipedia". Search tasks were designed following the principles of situated context (Borlund \& Ingwersen, 1999). Nine formal fact-finding tasks (described in Table 1) were defined based on previous research on information search (Choo, Detlor, \& Turnbull, 2000; Toms et al., 2007) in order to make the participants use the most frequent gestures (left and right clicking, zooming in/out, scrolling, using keyboard).

d) Task performance. Performance in search tasks was based on both task efficacy and efficiency. Task efficacy was a function of the number of tasks successfully achieved. For each task, participants were given one point for providing a right answer (or reached the expected target), and zero point for a wrong answer or no answer. Scores were summed across all tasks in order to compute an overall efficacy score. Time spent on each task, number of pages visited, number of left and right clicks were measured to account for task efficiency.

e) Protocol. This exploratory study was held in our research center's usability lab. Upon arrival, participants were asked to read and sign a consent form and randomly assigned to one of the two conditions (laptop or tablet com- 
Table 2 a Differences in means $(S D)$ of the main dependent variables between laptop $(N=33)$ and tablet computer $(N=36)$ conditions

\begin{tabular}{lllccc}
\hline & Device & Mean & $t$ & $d f$ & $p$ \\
\hline Efficacy & Laptop & $.6970(.1595)$ & 2.204 & 67 & .031 \\
& Tablet PC & $.5898(.239)$ & & & \\
Time per task (sec) & Laptop & $116.14(56.17)$ & 1.194 & 67 & .237 \\
& Tablet PC & $132.84(59.68)$ & & & \\
Pages visited per task & Laptop & $4.74(1.99)$ & .747 & 67 & .458 \\
& Tablet PC & $4.34(2.41)$ & & & \\
L Clicks & Laptop & 180.91 & .748 & 66 & .457 \\
& TabletPC & 168.83 & & & \\
R Clicks & Laptop & 14.06 & 5.828 & 66 & $<.001$ \\
& Tablet PC & 3.51 & & & \\
\hline
\end{tabular}

Note. Means are averaged over the all tasks, unless otherwise stated;

$d f$ : degrees of freedom.

puter). They filled out a biographical data form including familiarity scales. Instructions were then provided, and they were asked to complete a trial task before doing the search tasks, provided in a linear order. They were instructed to only use the default online browser to seek information. Once all the tasks were completed, participants were given time to debrief the study and escorted from the lab. On average, an experimental run took around sixty minutes.

f) Apparatus. In the two experimental conditions, we used a Lenovo Yoga 13 tablet computer PC with an Intel Core i7 and 8GM RAM[1]. The computer ran windows 8 and used Internet Explorer as the default internet browser. The monitor had a 13.3 inch screen with a resolution of $1600 \times 900$. In the touchscreen condition, the tablet computer PC was folded so that participants were only provided with the tactile touchscreen to interact with the device (so as to simulate a 'true' tablet computer). In the laptop condition, participants were asked to use the integrated mouse and keyboard and were not allowed to use the touchscreen. Interactions with the device and pages visited were recorded using third party software EyeWorks (EyeTracking Inc, 2015). Logs were analyzed to compute performance metrics.

g) Data analysis. All data transformations were performed on the open-source software R (R Core Team, 2018) and statistical analyses used the statistical suite SPSS. All dependent variables showed a normality of distribution and thus parametric independent-samples t tests were run to compare differences of mean between groups.

\section{Results}

The present exploratory study was designed to determine the effect of using a tablet computer versus a laptop on information search performance. Independent samples ttest were used to analyze the differences in scores across the two conditions. Table 2 provides means and standard deviations for the main behavioral metrics as well as the tstatistics and corresponding p-values. From the data, we can see that laptop users outperformed tablet computer users with a mean efficacy score of 0.69 ( $S D=.16$ ) compared to $0.59(S D=.24)$ (maximum score $=1$ ). No differences were found in time, number of pages visited or in number of left clicks (task efficiency). However, there was a significant difference in the number of right clicks with a mean of 14.06 in the laptop condition versus only 3.51 in the tablet computer condition. This last result seems to indicate that users did not know how to perform a right click on a tablet computer (holding the finger on the screen for a few seconds) or struggled with that action.

\section{Discussion}

This first study opened the door to further investigation by raising some interesting issues. While we found an effect of the device on performance, the underlying mechanisms that could explain this difference remain unexplored. It is noteworthy that laptop users visited more pages but took less time overall, which suggests that tablet computers users spent more time on each page. This might be explained by the fact that users were more disoriented in the search due to the increased mental effort required by the use of a tablet computer.

Building on these findings, a second study was conducted to examine the impact of the devices on the users' mental resources and performance. The objectives and hypotheses of this experiment are outlined in the next section. Specific theoretical framework is described before each hypothesis. 


\section{Experiment 2}

\section{Objectives and hypotheses}

Cognitive theories constitute a relevant framework to explore how tablet computers can impact users' mental resources. Originally developed in the field of instructional design, Cognitive Load Theory (Sweller, 1988) and her sister theory, the Cognitive Theory of Learning with Media (Mayer, Heiser, \& Lonn, 2001), are based on the same assumptions. Firstly, the human cognitive architecture is made up of two dependent structures: a) the working memory that actively selects and integrates incoming information with prior knowledge and mental models; b) a long-term memory that stores a potentially unlimited amount of information in the form of schemata. Secondly, the working memory has limited resources, and activities that request attention compete for these resources. Cognitive load refers to this limited capacity and is described as the mental cost of a specific task, for a particular individual in a given context (Sweller, 1988). According to these theories, cognitive load is multifactorial and can be divided into three types of cognitive load: intrinsic, extraneous and germane loads. Intrinsic load is related to the material to be learnt (the interactivity of the elements) and the user's prior knowledge. It is usually related to the task demand and task difficulty. Extraneous load deals with the mental resources devoted to elements that are not directly related to the task at hand and is often linked to the presentation format. Germane load is described as the mental resources required by schemata acquisition and automation in working memory. Korbach, Br"unken, and Park (2018) propose to consider the updated cognitive load theory model (Choi, van Merrienboer, \& Paas, 2014) which takes into account only two of those three cognitive loads (intrinsic and extraneous load) because of the close relationship between intrinsic and germane load, and therefore the inability to distinguish the contributions of one from the other. Since the working memory capacity is limited, an increase of extraneous load is correlated to a decrease of intrinsic and germane load and, consequently, results in lower learning outcomes or performance.

As mentioned in the rationale behind the first study, browsing the web on a tablet computer is likely to increase webpage scrolling, which will result in a higher demand upon cognitive resources and a rise in extraneous load. Moreover, keying errors are more frequent on onscreen keyboards than on their physical equivalents and therefore, require much more attentional resources. As pointed out by Sharit and colleagues (Sharit et al., 2008), information search on the web requires the employment of a substantial amount of mental resources. The seeker has to keep the goal of the search in working memory while making decisions about the search results' relevance until the task is successfully achieved. Given that, using tablet computers seems to require more mental resources, and the working memory has a very limited capacity. This is why it might be assumed that the use of a tablet computer hinders user performance.

Accordingly, the following set of hypotheses is stated:

$H_{1}$. Laptop users will outperform tablet computers users in online search.

$\mathrm{H}_{2}$. Using a tablet computer will generate a higher level of extraneous load compared to a laptop.

As pointed out by Sweller (2010), a rise in the level of extraneous load does not always result in a drop in performance. Since intrinsic load refers to the mental resources devoted to the task, we assume that the level of intrinsic load will be constant for a given information search task, regardless of the device used. Conversely, intrinsic load should increase with the level of task difficulty. Therefore, the two following hypotheses are made:

$H_{3 a}$. The level of intrinsic load will not vary across the devices.

$H_{3 b}$. The level of intrinsic load will increase with the level of task difficulty.

Under low intrinsic load conditions, an individual may deal with a high extraneous load without any impact on the performance, since the overall load does not exceed the working memory capacity. However, under moderate to high intrinsic load conditions, it is more likely that a high level of extraneous load will be detrimental to performance. Thus, it is reasonable to argue that a difference in performance between laptop and tablet computer users is more likely to be found for difficult tasks rather than for simple ones. Applied to the current study, it is hypothesized that there will be an interaction effect between the task difficulty and the type of device.

$H_{4}$. Tablets hinder performance in information search but only for difficult tasks.

\section{Method}

a) Sample. Sixty undergraduate students from a Belgian university took part in this study. None of the participants had taken part in the first study. They were enrolled on a psychology course and recruited through an online platform dedicated to research in social science. As in the first experiment, participants were randomly assigned to one of the two conditions (laptop or tablet computer). Four participants were removed due to technical problems encountered during the experiment. Our final sample was composed of 36 females and 18 males (mean age $=21.07$, $S D=1.87$ ). Participants had normal or corrected-tonormal vision and did not report any attentional disorder. 
Table 3 - Tasks instructions, goals and difficulty level

\begin{tabular}{lll}
\hline Task & Instructions & Task Demand \\
\hline 1 & Go the European Union (EU) portal on Wikipedia & Low \\
2 & Find what are the main European institutions & Low \\
3 & Find what is the motto of the EU & Low \\
4 & Find the name of the Head of EU international affairs & Low \\
5 & Identify what the ultra-peripheral region of EU and the countries they belong to & High \\
6 & $\begin{array}{l}\text { Find the EU member states GDP and count the number of countries with a higher GDP } \\
\text { than Belgium }\end{array}$ & High \\
7 & $\begin{array}{l}\text { Find the countries that founded the European Coal and Steel Community and the official } \\
\text { languages of those countries }\end{array}$ \\
8 & $\begin{array}{l}\text { In the main EU Wikipedia page. Find the Fondation that was named after one of the EU } \\
\text { founders. }\end{array}$ & High \\
\hline
\end{tabular}

They were given compensation of $€ 10$ (\$11) for participating in the experiment. This study was approved by the Institutional Review Board of the Université Libre de Bruxelles with written informed consent from all subjects in accordance with the Declaration of Helsinki.

b) Control variables. As in the first study, familiarity with laptop and tablet computer as well as familiarity with the gestures were controlled for. Independent samples t-tests did not yield any significant differences between experimental conditions.

c) Information search tasks. Participants were asked to search on the online encyclopedia Wikipedia. Several factfinding tasks were designed following the principles of situated context (Borlund \& Ingwersen, 1999). Tasks included reaching a specific page on Wikipedia, locating and finding piece(s) of information or comparing information across charts on the same page. Unlike the first study, tasks were classified into two blocks depending on their level of cognitive demand (Table 3).

According to Sharit et al.'s (2008) model of information search, working memory plays an important role in search performance. Throughout the process, users must keep the goal of the search in working memory while generating queries, selecting webpages and retrieving relevant content. Therefore, both the amount of information that has to be maintained in working memory and the remaining resources available to handle the task can impact the performance in the information search. The tasks were designed to manipulate the amount of information that has to be kept in working memory. For the low demanding tasks (single fact-finding task), this amount is kept minimal as the user has to maintain a single piece of information in working memory while browsing webpages to locate information that meets the goal of the search. For the high demanding tasks (comparing information between webpages), the user has to maintain a greater amount of information in working memory along with monitoring the search itself, leading to an overall increase in task-related cognitive demand. To ascertain the level of task complexity, participants were asked to gauge the task difficulty after each task. Participants across the two conditions found the low-demanding block of tasks to be less difficult than the high-demanding one.

d) Task performance. Participants were awarded one point for a successfully achieved task and zero point for a wrong answer or no answer; the sum of points corresponds to the score of efficacy. Like the first study, efficiency was measured by means of four metrics: time spent on task, number of webpages visited, and number of left and right clicks. The total of all the task scores was calculated in order to give an overall score for efficacy or for/and efficiency. To account for task demand, scores were added up for each of the two task blocks (that being low and high demanding).

e) Cognitive load measurement. Different methods allow the measurement of cognitive load: subjective ratings, performance-based measures and psychophysiological measures (see Brunken, Plass, \& Leutner, 2003; Galy, Cariou, \& Mélan, 2012, for a review of these methods).

Perceived cognitive load was measured with a twoitem scale adapted from previous studies (Cierniak, Scheiter, \& Gerjets, 2009; Gerjets, Scheiter, \& Catrambone, 2004; Scheiter, Gerjets, \& Catrambone, 2006). The items were adjusted to reflect the variations of the loads in the specific context of this study. Intrinsic load was assessed with an item referring to the mental effort required to achieve tasks goals. Extraneous load was assessed with an item related to the mental effort devoted to interacting with the device. All items were measured by a 7-point Likert scale ranging from "Strongly disagree" to "Strongly agree”.

Psychophysiological measures have several advantages over subjective ratings. Since they are based on bodily responses, they allow measurement at a high rate and with 
a high degree of sensitivity (Galy et al., 2012). Moreover, they do not require an overt response by the subjects and, in this way, are considered as a direct and "objective" way to infer mental activity. Although many measures have been used to estimate mental workload (e.g. cardiac activity, galvanic skin response, event-related brain changes), eye-related measures are amongst the most popular used ones so far. Eye tracking is a cost effective and a nonintrusive technique that allows to monitor users' attention, processing demand and mental workload. Cognitive activity can be inferred from three classes of eye information: eye movements (fixations and saccades), eye blink and pupillary response (Chen \& Epps, 2012; Holmqvist et al., 2011; Isabella, Urbain, Cheyne, \& Cheyne, 2019).

Although there is still no evidence of direct relationship between physiological measures and independent measures of subtypes of load (Zheng, 2018), this is still an ongoing research and such attempts should be encouraged (Sweller, 2018). In this study, we investigated whether we could identify independent proxies of intrinsic and extraneous loads using eye-related data.

Fixation duration is assumed to be a measure of processing demand and longer fixations and have been related to higher cognitive load in many studies (Holmqvist et al., 2011). Korbach et al. (2018) showed that fixation duration, amongst other eye movements such as saccades and transitions, should be seen as indicators of cognitive activity that provide information about what causes the cognitive load. Therefore, we assumed that, in the particular context of this study, fixation duration would be related to variation of task complexity and therefore could be seen as a proxy of the intrinsic load.

Unlike eye movements, the pupillary response is under control of the autonomous system and cannot be voluntarily controlled by the subject, which explains why it has been one of the most extensively studied eye-related measures. Relationships between pupil diameter and cognitive load can also be found in numerous studies interested in web user's behavior (Debue \& Van De Leemput, 2014; Di Stasi, Antolí, \& Cañas, 2013; Gwizdka \& Zhang, 2015). An increase of pupil diameter might well be related to a deeper cognitive processing or higher user activation in the task. The Index of Cognitive Activity (ICA) is a pupilbased composite measure intended to filter out the variations in pupil diameter caused by changes in luminance (see Marshall, 2002, for an in-depth explanation). While so far the ICA has been used in a limited number of studies, it has been shown to be sensitive to changes in perceptual demand (Schwalm, Keinath, \& Zimmer, 2008). In this study, we investigated whether the ICA could be used as a proxy measure of the extraneous load. f) Protocol. A similar protocol as in the first study was used, except that the eye tracking device was calibrated for each participant before the test session. Subjective ratings of cognitive load were collected after each block of tasks while task difficulty was assessed after each task. The presentation order of the blocks was randomized between subjects to avoid any order effect.

g) Apparatus. The study setting was similar to the first study and the same computer was used. The eye tracking data was collected using the FaceLab 5 remote system (SeeingMachines), with binocular tracking at a sampling rate of $60 \mathrm{~Hz}$. The system consists of two small cameras and an infra-red spotlight that were situated below the screen. The proprietary software EyeWorks (EyeTracking Inc, 2015) was used for collecting raw eye data and computing the Index of Cognitive Activity. Data was then imported into the open-source eye tracking data analysis software OGAMA (Vosskühler, Nordmeier, Kuchinke, \& Jacobs, 2008) and means were computed across tasks and participants using data from both eyes. Minimum fixation duration and the size of the detection ring were set to 100 milliseconds and 40 pixels respectively (the expression in pixels of the system accuracy $\left(1^{\circ}\right)$ ). Because of calibration problems and artefacts, 25 participants were removed from the eyerelated data analyses.

h) Data analysis. All data transformations were performed on the open-source software R (R Core Team, 2018). Pearson's correlation analysis and descriptive statistical analyses were used for the statistical suite SPSS. After removing outliers, normality tests indicated that the variables included in the analyses were approximately normally distributed. Linear Mixed Models (LMM) tested the main effects of the device and task demand as well as the interaction between both variables (see West, Welch, \& Galecki, 2014, for a comprehensive introduction to LMM). Unlike the General Linear Model, LMM allows to define random effects along with fixed effects in order to account for the variability across subjects (random intercept model) or the variability across the subject's responses to the main effect (random slope model). Following the recommendations of Barr, Levy, Scheepers, and Tily (2013) and Schielzeth and Forstmeier (2009), we used a maximal random effect structure with random intercept and random slope for the main between-subject effect (device), with an unstructured covariance matrix between random effects. Convergence issues were dealt with by removing the random intercept from the model and keeping the random slope(s) in order to minimize the type 1 error (Schielzeth \& Forstmeier, 2009). 
Table 4 ॥ Linear mixed effects model summary for performance metrics

\begin{tabular}{llcccc}
\hline & Parameters & Estimates $(\beta)$ & $S E$ & $p$ & AIC \\
\hline Efficacy & Intercept & 2.489 & .076 & $<.001$ & 753.428 \\
& Device & 0.334 & .109 & .002 & \\
& Task demand & 0.351 & .100 & .728 & \\
& Device $\times$ task demand & -0.2689 & .14 & .069 & \\
Time & Intercept & 171.30 & 10.138 & $<.001$ & 3963.392 \\
& Device & -39.510 & 14.67 & .009 & \\
& Task demand & -55.70 & 9.96 & $<.001$ & \\
& Device $\times$ task demand & 38.147 & 14.63 & $<.01$ & \\
Pages & Intercept & 3.058 & .165 & $<.001$ & 1309.177 \\
& Device & -.0983 & .237 & $<.001$ & \\
& Task demand & -.4992 & .232 & .037 & \\
& Device $\times$ task demand & 1.0266 & .339 & .004 & \\
& Intercept & 9.74 & .439 & $<.001$ & 1791.869 \\
& Device & -.909 & .642 & .162 & \\
& Task demand & .269 & .573 & .640 & \\
& Device $\times$ task demand & -.446 & .848 & .602 & \\
& Intercept & 0 & .011 & 1.00 & -507.971 \\
& Device & .034 & .016 & .032 & \\
& Task demand & 0 & 0.16 & 1.00 & \\
& Device $\times$ task demand & -.019 & .023 & .415 & \\
\hline
\end{tabular}

Note. $S E$ : Standard Errors; AIC: Akaike's Information Criterion

\section{Results}

a) Task Performance. As in the first experiment, we found a significant main effect of the device on efficacy ( $B=0.334, p=.002$ ), showing that tablet computer participants performed significantly worse $(M=2.50, S D=$ 0.78 ) than laptop participants ( $M=2.79, S D=.59$ ) (maximum $=3$ ). While the predicted two-way interaction between device and task difficulty failed to reach the significance threshold ( $B=-0.27, S E=.14, p=0.69$ ), the results tended to support that only high-demanding tasks lead to a difference in performance between devices $\left(H_{4}\right)$.
As indicated in Tables 4 and 5, tablet computer participants spent on average more time on tasks than laptop participants ( $B=-39.51, S E=14.67, p=.009$ ), but only when performing high-demanding tasks. Similarly, tablet computer users visited more webpages than laptop users when they tried to complete high-demanding tasks $(B=1.02, S E=.339, p=.004)$.

b) Subjective ratings of cognitive load. Descriptive statistics and the results of linear mixed models analyses for subjective cognitive loads are presented in Tables 6 and 7. As expected, no main effect of the device on the level of reported intrinsic load was found ( $H_{3 a}$ is supported).

Table 5 - Differences in means ( $S D$ ) of efficacy and efficiency across conditions and task demand

\begin{tabular}{lcccccc}
\hline \multicolumn{1}{l}{} & & Efficacy & Time (seconds) & Webpages visited & Left clicks & Right clicks \\
\hline Laptop & & & & & & \\
\hline Total & & $2.73(.59)$ & $123.49(65.69)$ & $2.30(1.21)$ & $8.76(2.46)$ & $.03(.160)$ \\
Task demand & Low & $2.60(.71)$ & $111.91(62.79)$ & $2.60(1.45)$ & $8.66(2.78)$ & $.01(.122)$ \\
& High & $2.83(.47)$ & $132.02(66.79)$ & $2.07(.91)$ & $8.84(2.19)$ & $.03(.184)$ \\
Tablet PC & & & & & & \\
Total & & $2.50(.78)$ & $143.96(89.54)$ & $2.83(1.85)$ & $9.85(4.29)$ & $0(0)$ \\
Task demand & Low & $2.52(.78)$ & $116.20(72.75)$ & $2.56(.132)$ & $10.01(4.77)$ & $0(0)$ \\
& High & $2.49(.79)$ & $167.28(95.82)$ & $3.05(2.17)$ & $9.71(3.85)$ & $0(0)$ \\
\hline Low demand & & $2.55(.74)$ & $114.25(68.22)$ & $2.58(1.38)$ & $9.41(4.05)$ & $.01(.081)$ \\
High demand & $2.65(.68)$ & $150.103(84.61)$ & $2.34(1.43)$ & $9.30(3.19)$ & $.02(.127)$ \\
\hline
\end{tabular}


Table 6 - Linear mixed effects model summary for subjective ratings of cognitive load

\begin{tabular}{llcccc}
\hline & Parameters & Estimates $(\beta)$ & $S E$ & $p$ & AIC \\
\hline Intrinsic Load & Intercept & 3.36 & .25 & $<.001$ & 517.126 \\
& Device & -0.90 & .36 & .801 & \\
& Task demand & -0.40 & .24 & .095 & \\
& Device $\times$ task demand & .64 & .35 & .073 & \\
Extraneous Load & Intercept & 3.69 & .24 & $<.001$ & 540.691 \\
& Device & -0.89 & .35 & .013 & \\
& Task demand & -1.04 & .28 & $<.001$ & \\
& Device $\times$ task demand & .92 & .41 & .025 & \\
\hline
\end{tabular}

Note. SE : Standard Errors; AIC: Akaike’s Information Criterion

Table 7 [ Differences in means (SD) of reported levels of cognitive loads across conditions and level of task demand

\begin{tabular}{lllc}
\hline & & Intrinsic Load & Extraneous Load \\
\hline Laptop & & & \\
\hline Total & $3.36(1.50)$ & $2.75(1.34)$ & \\
Task demand & Low & $3.46(1.47)$ & $2.63(1.31)$ \\
& High & $3.31(1.52)$ & $2.82(1.36)$ \\
Tablet PC & & & \\
\hline Total & $3.27(1.46)$ & $3.35(1.71)$ & \\
Task demand & Low & $3.00(1.55)$ & $2.69(1.41)$ \\
& High & $3.42(1.40)$ & $3.74(1.76)$ \\
\hline Low demand & $3.21(1.52)$ & $2.66(1.35)$ & \\
High demand & $3.36(1.45)$ & $3.28(1.63)$ & \\
\hline
\end{tabular}

Participants reported having devoted the same amount of mental effort to the task, regardless of the device used. Surprisingly, no difference in intrinsic load was found relative to the level of task demand though we expected that intrinsic load would increase with task difficulty (H3b is not supported). Interestingly, we found a significant interaction between the device and the task demand ( $B=0.92$, $S E=.28, p=.025$ ) showing that tablet computer users reported a significantly higher level of extraneous load $M=3.74, S D=1.76$ ) than laptop users $(M=2.82$, $S D=1.36$ ) but only for high-demanding tasks. A possible explanation of these results may be that high-demanding tasks made the seekers use more complex gestures such as performing right clicks or zooming in and out. Because tablet computer users were less familiar with these gestures, they reported having devoted more mental effort in the interaction with the device.

A Pearson's correlational analysis was conducted to examine the relationships between the different types of load, for each level of task demand. Correlations for lowdemanding tasks indicated a positive relationship between extraneous (EL) and intrinsic load (IL) $(r=.592, p<.001)$. Similarly, correlations for high-demanding tasks indicated a positive relationship between EL and IL $(r=.588, p=<$ $.001)$. c) Objective measures of cognitive load. We suggested that fixation duration might be a close proxy of intrinsic load although ICA would reflect variations in extraneous load. As expected (see Tables 8 and 9), we found a main effect of task demand on fixation duration $(B=-11.11$, $S E=3.93, p=.005$ ) showing that high-demanding tasks led to longer fixations ( $M=172.84, S D=25.41$ ) than low-demanding tasks ( $M=162.82, S D=20.26)$. No significant effect was obtained for the device and no interaction was found. We did not find any effect of task demand nor the device on the ICA. A Pearson's correlation analyses revealed that there were no significant relationships between the eye-related data, regardless of the level of task demand.

\section{Discussion}

Task performance.Taken together, these results suggest that searching on a tablet computer required more effort with, for the very same task instructions, more webpages visited and more time spent to achieve a lower efficacy. Although we expected that tablet computer would decrease pointing accuracy, no difference in the number of left clicks was found between devices. This may be explained by the relative simplicity of the tasks being performed, since the participants mainly had to click on hy- 
Table 8 a Linear mixed effects model summary for fixation duration and ICA

\begin{tabular}{lllllc}
\hline & Parameters & Estimates $(\beta)$ & $S E$ & $p$ & AIC \\
\hline Fixation Duration & Intercept & 169.75 & 3.73 & $<.001$ & 2182.89 \\
& Device & 5.65 & 5.07 & .271 & \\
& Task demand & -11.11 & 3.93 & .005 & \\
\multirow{4}{*}{ ICA } & Device $\times$ task demand & 2.74 & 5.42 & .613 & \\
& Intercept & .489 & .013 & $<.001$ & 1226.372 \\
& Device & -.033 & .017 & .064 & \\
& Task demand & -.0015 & .006 & .819 & \\
& Device $\times$ task demand & -.010 & .008 & .250 & \\
\hline
\end{tabular}

Note. SE : Standard Errors; AIC: Akaike’s Information Criterion.

Table 9 a Differences in means (SD) in fixation duration and ICA across conditions and level of task demand

\begin{tabular}{lccc}
\hline \multicolumn{3}{l}{ Fixation Duration (milliseconds) } & ICA (system unit) \\
\hline Laptop & & & \\
\hline Total & & $171.55(23.55)$ & $0.448(.053)$ \\
Task demand & Low & $166.35(20.38)$ & $0.444(.052)$ \\
& High & $175.35(25.01)$ & $0.451(.053)$ \\
Tablet PC & & & \\
\hline Total & & $165.02(23.71)$ & $.0486(0.57)$ \\
Task demand & Low & $158.94(19.59)$ & $0.487(.055)$ \\
& High & $169.84(25.67)$ & $0.484(5.92)$ \\
\hline $\begin{array}{l}\text { Low demand } \\
\text { High demand }\end{array}$ & & $162.82(20.26)$ & $0.463(.058)$ \\
\hline
\end{tabular}

perlinks to navigate webpages. Nevertheless, it may also show that users have integrated the basics of the touchscreen interaction mode and that they are able to use the left click effortlessly and with high accuracy. Conversely, our results indicated that almost no right clicks were performed on the tablet computer condition which is consistent with the findings from the first study. This difference could be attributed to the fact that the users did not know how to perform a right click on a touchscreen (press and hold). However, this extremely low number of clicks casts some doubt on the validity of the measures collected and the possibility of a measurement issue cannot be ruled out. Subjective rating of cognitive load.The strong correlations between IL and EL indicate that these items were likely to measure the same construct rather than being impacted by separate factors. Even though scales using a single item for each type of load have been reported in the literature (see De Jong, 2010), it may not allow users to distinguish between different types of load. Although, tablet computer group reported having devoted more mental effort than laptop users which tends to support our main assumptions.

Objective measures of cognitive load.The ICA was higher in the tablet computer condition $(M=0.486, S D=.057)$ than in the laptop condition ( $M=0.448, S D=.053)$, although this difference was just above the significance threshold ( $B=-.033, S E=.017, p=0.64$ ). One may argue that this represents a rather small variation, but these results are in line with previous findings (Matthews et al., 2015; Schwalm et al., 2008; Debue \& Van De Leemput, 2014) that found similar ranges in ICA variations. Nevertheless, it is possible that ICA failed to capture subtle variations in perceptual load across devices and might be more suited to discriminating between more dissimilar testing scenarios such as doing simple cognitive tasks versus driving simulations (Marshall, 2002). It has been recently demonstrated that several mental workload levels can be discriminated via electroencephalogram (EEG) (Tremmel et al., 2019). Therefore, EEG measures should be considered to distinguish cognitive load across devices.

Similarly, the results showed that users had longer fixations while performing high demanding tasks, which could reflect deeper information processing and thus, higher intrinsic load. However, due to methodological limitations, this study did not account for the particular activities involved during the information search tasks. Future studies would benefit from investigating fixation duration for each stage of the information search process (querying, comparing results, keying information) to confirm or infirm these preliminary results. 
Because cognitive load was measured with two different methods, it is impossible to clearly confirm all of our hypotheses. Nevertheless, the two measures of extraneous load point towards the same conclusion, showing that tablet computers required more mental effort $\left(H_{2 a}\right.$ is supported). With regard to intrinsic load, fixation duration and the self-reported measure showed the expected behavior, while the latter was not significant $\left(H_{3 a} \& H_{3 b}\right.$ are partially supported).

\section{General Discussion}

Tablet computer use has been rapidly increasing in educational settings over the last few years. Despite this growth, very few evidence-based studies have investigated whether students benefited from tablet computer use when compared to traditional computers and laptops. Though, previous research has shown that tablet computers might not be suited for every activity due to their smaller screen size, the touchscreen interaction mode and the onscreen keyboard. The present study sought to offer a closer look at the impact of tablet computer use versus laptop use on the efficacy, efficiency and cognitive load when performing a web-based search.

The most interesting finding was that in two separate experiments, we found that laptop users outperformed tablet computer users on task efficacy. As suggested by the data of our second study, the drop in performance is related to level of task difficulty. Search tasks that were low-demanding and perceived as easy did not result in a difference in performance. On the other hand, it seems that when tasks are more demanding, the demand of the task (intrinsic load) interferes with the extra resources devoted to the use of the tablet computer. Likewise, efficacy results showed no difference across devices in time spent on tasks or the number of webpages consulted for the lowdemanding tasks. On the contrary, tablet computer users spent more time and visited more webpages when conducting high-demanding tasks than laptop users.

It was assumed that since tablet computers feature touchscreens, pointing would be less accurate and would result in a higher number of left clicks. However, the current undertaking did not find any difference in the number of left clicks. It might be concluded that tablet computer users are now used to interact with simple gestures effortlessly. On the other hand, data indicated that there were far fewer right clicks on the tablet computer than on the laptop. It may be because users did not know how to perform this action on a touchscreen, showing that more complex gestures are not yet widely mastered. A note of caution is due here since we cannot rule out the possibility of recording issues in the tablet computer condition.

As shown in the results, participants using the tablet computer to seek information on Wikipedia reported having devoted more mental resources in using the device (extraneous load) than those on the laptop. Moreover, the pupil-based index of cognitive activity (ICA) showed a similar trend with higher values in the tablet computer condition. This study provides some food for thought about what physiological measures should be explored to identify objective proxies of specific cognitive load factors. In this sense, it represents an attempt to identify objective indicators of cognitive load subtypes, as suggested by Sweller (2018). Though, these proxies remain specific to the particular context of information search on hypermedia.

As with any experimental research, this one has limitations. First, the participants for this research were firstyear college students, a population in which one can expect to find both experienced tablet computer users and those unfamiliar with the device. The results may differ with a younger population who may be more familiar with this technology due to earlier initial exposure (Margolin, Driscoll, Toland, \& Kegler, 2013). Second, our test scenarios consisted of assigned fact-finding tasks on Wikipedia. It is likely that ill-defined fact-finding tasks or broader information-gathering tasks would make users set more complex strategies that impose a higher burden on working memory. In this context, the impact tablet computers have on performance may be exacerbated. Third, it must be noted that, for technical reasons, a touchscreen laptop was used to simulate the use of a tablet computer. Thus, the screen size was similar in both experimental conditions which affected the amount of information able to be displayed. It is likely that if using 7" or a 10" tablet computers, participants would have scrolled more often to locate information. Far from discrediting our research, this reinforces our findings and indicates that even with larger screens (13"), touchscreen devices can be detrimental to performance in online search. Nonetheless, our study should be replicated using an actual commercial tablet computer. Lastly, the artificial nature of a controlled lab study limits the generalizability of the findings.

Unlike many other studies that focus more on user's perceptions of devices, this study makes a contribution to the field of research by offering a comparative study of the impact of device use on actual user performance. The present research has shown that the device used to search online can impact students' performance. Regardless of this it is undeniable that tablet computers, thanks to their portability, usability, and interactivity have the potential to be of great benefit in the world of education. Even so, they might not be suited to every activity required in the classroom and special care needs to be taken when introducing new technology into the school environment. Further research should be conducted to investigate what are the 
drivers of students' interest in using tablet computers for scholastic purposes.

\section{References}

Ando, M., \& Ueno, M. (2011). E-learning using tablet pc. In EICM (Ed.), Proceedings of world conference on e-learning in corporate, government, healthcare, and higher education (pp. 2157-2166). Washington, DC.

Barr, D. J., Levy, R., Scheepers, C., \& Tily, H. J. (2013). Random effects structure for confirmatory hypothesis testing: Keep it maximal. Journal of Memory and Language, 68(3), 255-278. doi:10.1016/j.jml.2012.11.001

Borlund, P., \& Ingwersen, P. (1999). The application of work tasks in connection with the evaluation of interactive information retrieval systems: Empirical results. Scotland: In Proceedings of MIRA'99. Glasgow.

Botella, F., Moreno, J. P., \& Peñalver, A. (2014). How efficient can be a user with a tablet versus a smartphone? In ACM (Ed.), Proceedings of the 15th international conference on human computer interaction (64:1-64:9). doi:10.1145/2662253.2662317

Brunken, R., Plass, J. L., \& Leutner, D. (2003). Direct measurement of cognitive load in multimedia learning. Educational Psychologist, 38, 53-61. doi:10 . 1207 / S15326985EP3801_7

Chaparo, B., Nguyen, B., Phan, M., Smith, A., \& Teves, J. (2010). Keyboard performance: Ipad versus netbook. Retrieved from http://usabilitynews.org/keyboardperformance-ipad-versus-netbook/

Chen, S., \& Epps, J. (2012). Automatic classification of eye activity for cognitive load measurement with emotion interference. Computer Methods and Programs in Biomedicine, 110(2), 111-124. doi:10 . 1016/j . cmpb . 2012.10.021

Choi, H. H., van Merrienboer, J. J. G., \& Paas, F. (2014). Effects of the physical environment on cognitive load and learning: Towards a new model of cognitive load. Educational Psychology Review, 26, 225-244. doi:10 . 1007/s10648-014-9262-6

Choo, C. W., Detlor, B., \& Turnbull, D. (2000). Information seeking on the web: An integrated model of browsing and searching. First Monday, 5, 729-729. doi:10.5210/ fm.v5i2.729

Chou, P. N., \& Feng, S. T. (2019). Using a tablet computer application to advance high school students' laboratory learning experiences: A focus on electrical engineering education. Sustainability, 11(2), 381-381. doi:10 . 3390/su11020381

Churchill, D., Fox, B., \& King, M. (2012). Study of affordances of ipads and teachers' private theories. International Journal of Information and Education Technology, 2(3), 251-251. doi:10.7763/IJIET.2012.V2.122
Cierniak, G., Scheiter, K., \& Gerjets, P. (2009). Explaining the split-attention effect: Is the reduction of extraneous cognitive load accompanied by an increase in germane cognitive load? Computers in Human Behavior, 25, 315-324. doi:10.1016/j.chb.2008.12.020

De Jong, T. (2010). Cognitive load theory, educational research, and instructional design: Some food for thought. Instructional science, 38(2), 105-134. doi:10. 1007/s11251-009-9110-0

Debue, N., \& Van De Leemput, C. (2014). What does germane load mean? an empirical contribution to the cognitive load theory. Frontiers in Psychology, 5, 1099-1099. doi:10.3389/fpsyg.2014.01099

Di Stasi, L. L., Antolí, A., \& Cañas, J. J. (2013). Evaluating mental workload while interacting with computer-generated artificial environments. Entertainment Computing, 4(1), 63-69.

EyeTracking Inc. (2015). Eyeworks. CA, USA: Solana Beach. Fernández-Lopez, Á., Rodriguez-Fórtiz, M. J., RodríguezAlmendros, M. L., \& Martínez-Segura, M. J. (2013). Mobile learning technology based on ios devices to support students with special education needs. doi:10.1016/j. compedu.2012.09.014

Findlater, L., \& Wobbrock, J. O. (2012). From plastic to pixels: In search of touch-typing touchscreen keyboards. Interactions, 19(3), 44-49. doi:10 . 1145 / 2168931 . 2168942

Galy, E., Cariou, M., \& Mélan, C. (2012). What is the relationship between mental workload factors and cognitive load types? International Journal of Psychophysiology, 83(3), 269-275. doi:10.1016/j.ijpsycho.2011.09.023

Gerjets, P., Scheiter, K., \& Catrambone, R. (2004). Designing instructional examples to reduce intrinsic cognitive load: Molar versus modular presentation of solution procedures. Instructional Science, 32(1), 33-58. doi:10.1023/b:truc.0000021809.10236.71

Gwizdka, J., \& Zhang, Y. (2015). Differences in eye-tracking measures between visits and revisits to relevant and irrelevant web pages. In ACM (Ed.), Proceedings of the 38th international acm sigir conference on research and development in information retrieval ., ny, usa: Acm (pp. 811-814). doi:10.1145/2766462.2767795

Haßler, B., Major, L., \& Hennessy, S. (2016). Tablet use in schools: A critical review of the evidence for learning outcomes. Journal of Computer Assisted Learning, 32(2), 139-156. doi:10.1111/jcal.12123

Henderson, J. M., Shinkareva, S. V., Wang, J., Luke, S. G., \& Olejarczyk, J. (2013). Predicting cognitive state from eye movements. PLOS ONE, 8(5), e64937-e64937. doi:10.1371/journal.pone.0064937

Holmqvist, K., Nystr"om, M., Andersson, R., Dewhurst, R., Jarodzka, H., \& van de Weijer, J. (2011). Eye tracking: 
A comprehensive guide to methods and measures. Oxfored: Oxford University Press.

IDC. (2016). Mobility in workplace transformation: The anytime, anywhere office. Retrieved from http : / / www.idc.com/getdoc.jsp?containerId=AP41671616

Isabella, S. L., Urbain, C., Cheyne, J. A., \& Cheyne, D. (2019). Pupillary responses and reaction times index different cognitive processes in a combined go/switch incidental learning task. Neuropsychologia, 127, 48-56. doi:10.1016/j.neuropsychologia.2019.02.007

Karsenti, T., \& Fievez, A. (2013). The ipad in education: Uses, benefits, and challenges: A survey of 6057 students and 302 teachers in quebec, canada. Retrieved from http://www.karsenti.ca/ipad/pdf/iPad_report_ Karsenti-Fievez_EN.pdf

Kaur, A. (2013). Tracking the use of tablets in community colleges. Retrieved from http://www.itcnetwork.org/ resources/itc - newsletter / 769 - tracking - the - use - oftablet\%20computers-in-community-colleges.html

Kellar, M., Watters, C., \& Shepherd, M. (2007). A field study characterizing web-based information-seeking tasks. Journal of the American Society for Information Science and Technology, 58(7), 999-1018. doi:10.1002/asi. 20590

Korbach, A., Br"unken, R., \& Park, B. (2018). Differentiating different types of cognitive load: A comparison of different measures. Educational Psychology Review, 30, 503-529. doi:10.1007/s10648-017-9404-8

M"uller, H., Gove, J. L., Webb, J. S., \& Cheang, A. (2015). Understanding and comparing smartphone and tablet use: Insights from a large-scale diary study. In Proceedings of the annual meeting of the australian special interest group for computer human interaction ( $p$ (pp. 427-436). Washington, DC: ACM.

Marchionini, G. (1995). Information seeking in electronic environments. New York, NY, USA: Cambridge University Press.

Margolin, S. J., Driscoll, C., Toland, M. J., \& Kegler, J. L. (2013). E-readers, computer screens, or paper: Does reading comprehension change across media platforms? Applied Cognitive Psychology, 27(4), 512-519. doi:10.1002/acp.2930

Marshall, S. (2002). The index of cognitive activity: Measuring cognitive workload. In IEEE (Ed.), Proceedings of the 2002 ieee 7 th conference on human factors and power plants (pp. 5-9). doi:10 . 1109 / HFPP . 2002. 1042860

Matthews, G., Reinerman-Jones, L., Wohleber, R., Lin, J., Mercado, J., \& Abich, J. (2015). Workload is multidimensional, not unitary: What now? In S. D. \& C. Fidopiastis (Eds.), Foundations of augmented cognition (pp. 1-9). doi:10.1007/978-3-319-20816-9_5
Mayer, R. E., Heiser, J., \& Lonn, S. (2001). Cognitive constraints on multimedia learning: When presenting more material results in less understanding. Journal of Educational Psychology, 93(1), 187-198. doi:10. 1037/0022-0663.93.1.187

Mercier, E. M., Higgins, S. E., \& Joyce-Gibbons, A. (2016). The effects of room design on computer-supported collaborative learning in a multi-touch classroom. Interactive Learning Environments, 24(3), 504-522. doi:10.1080/10494820.2014.881392

Mulet, J., van de Leemput, C., \& Amadieu, F. (2019). A critical literature review of perceptions of tablets for learning in primary and secondary schools. $E d-$ ucational Psychology Review, 99, 1-32. doi:10.1007/ s10648-019-09478-0

Murphy, M. E. (2014). Why some schools are selling all their ipads.

Nguyen, L., Barton, S. M., \& Nguyen, L. T. (2015). Ipads in higher education-hype and hope. British Journal of Educational Technology, 46(1), 190-203. doi:10.1111/ bjet.12137

Ostrowski, C. (2014). Touching our way to better conversations: How tablets impact cognitive load and collaborative learning discourses. In M. Simonson (Ed.), Proceedings of the the annual convention of the association for educational communications and technology (vol (pp. 159-167). Jacksonville, FL: 1.

Percival, J., \& Claydon, T. (2015). A study of student and instructor perceptions of tablet pcs in higher education contexts. (pp. 250-264). Dublin, Ireland: ACM.

Project Tomorrow. (2017). The new learning leader - the emerging role of the agile school principal as digital evangelist. Washington, DC.: Trends in Digital Learning. Retrieved from https://tomorrow.org/speakup/ speakup_data_findings.html

$\mathrm{R}$ Core Team. (2018). $R$ : A language and environment for statistical computing. Vienna, Austria: R Foundation for Statistical Computing.

Reisinger, D. ( (2016). Maine schools dismiss ipads as "toys" ready macbooks instead.

Sachs, L., \& Bull, P. (2012). Case study: Using ipad2 for a graduate practicum course. In Proceedings of the society for information technology \& teacher education international conference (pp. 3054-3059). Chesapeake, VA: Association for the Advancement of Computing in Education.

Sanchez, C. A., \& Goolsbee, J. Z. (2010). Character size and reading to remember from small displays. Computers \& Education, 55(3), 1056-1062. doi:10 . 1016 / j . compedu.2010.05.001

Sanchez, C. A., \& Wiley, J. (2009). To scroll or not to scroll: Scrolling, working memory capacity, and compre- 
hending complex texts. Human Factors: The Journal of the Human Factors and Ergonomics Society, 51(5), 730-738. doi:10.1177/0018720809352788

Scheiter, K., Gerjets, P., \& Catrambone, R. (2006). Making the abstract concrete: Visualizing mathematical solution procedures. Computers in Human Behavior, 22(1), 9-25. doi:10.1016/j.chb.2005.01.009

Schielzeth, H., \& Forstmeier, W. (2009). Conclusions beyond support: Overconfident estimates in mixed models. Behavioral Ecology, 20(2), 416-420. doi:10.1093/ beheco/arn145

Schwalm, M., Keinath, A., \& Zimmer, H. D. (2008). Pupillometry as a method for measuring mental workload within a simulated driving task. In F. O. F. de Waard, B. Lorenz, \& K. A. Brookhuis (Eds.), D (pp. 1-13). Human Factors for assistance: Shaker Publishing.

Sharit, J., Hernández, M. A., Czaja, S. J., \& Pirolli, P. (2008). Investigating the roles of knowledge and cognitive abilities in older adult information seeking on the web. acm trans. Comput.-Hum. Interact, 15(1), 1-3. doi:10.1145/1352782.1352785

Sweller, J. (1988). Cognitive load during problem solving?: Effects on learning. Cognitive Science, 12(2), 257-285. doi:10.1207/s15516709cog1202_4

Sweller, J. (2010). Element interactivity and intrinsic, extraneous, and germane cognitive load. Educational Psychology Review, 22, 123-138. doi:10.1007/s10648-0109128-5

Sweller, J. (2018). The role of independent measures of load in cognitive load theory. In R. Z. Zheng (Ed.), Cognitive load measurement and application (pp. 3-7). doi:10 . 4324/9781315296258-1

Thatcher, A. (2008). Web search strategies: The influence of web experience and task type. Information Processing
\& Management, 44(3), 1308-1329. doi:10.1016/j.ipm. 2007.09.004

Toms, E. G., O’Brien, H., Mackenzie, T., Jordan, C., Freund, L., Toze, S., ... MacNutt, A. (2007). Task effects on interactive search: The query factor. In N. Fuhr, J. Kamps, M. Lalmas, \& A. Trotman (Eds.), Focused access to xml documents (pp. 359-372). doi:10.1007/9783-540-85902-4_31

Tremmel, C., Herff, C., Sato, T., Rechowicz, K., Yamani, Y., \& Krusienski, D. J. (2019). Estimating cognitive workload in an interactive virtual reality environment using eeg. Frontiers in Human Neuroscience, 10, 33893389. doi:10.3389/fnhum.2019.00401

Varcholik, P., LaViola, J., \& Hughes, C. (2012). Establishing a baseline for text entry for a multi-touch virtual keyboard. International Journal of Human-Computer Studies, 70(10), 657-672. doi:10.1016/j.ijhcs.2012.05. 007

Vosskühler, A., Nordmeier, V., Kuchinke, L., \& Jacobs, A. M. (2008). Ogama (open gaze and mouse analyzer): Open-source software designed to analyze eye and mouse movements in slideshow study designs. Behavior Research Methods, 40(4), 1150-1162. doi:10.3758/ BRM.40.4.1150

Wang, M., \& Shen, R. (2012). Message design for mobile learning: Learning theories, human cognition and design principles. British Journal of Educational Technology, 43(4), 561-575. doi:10.1111/j.1467-8535. 2011. 01214.x

West, B. T., Welch, K. B., \& Galecki, A. T. (2014). Linear mixed models: A practical guide using statistical software, second edition. Racoon City: CRC Press.

Zheng, R. Z. (2018). Cognitive load measurement and application. doi:10.4324/9781315296258

\section{Citation}

Debue, N., Oufi, N., \& van de Leemput, C. (2020). An investigation of using a tablet computer for searching on the web and the influence of cognitive load. The Quantitative Methods for Psychology, 16(3), 226-239. doi:10.20982/tqmp.16. 3.p226

Copyright $\odot$ 2020, Debue, Oufi, and van de Leemput. This is an open-access article distributed under the terms of the Creative Commons Attribution License (CC BY). The use, distribution or reproduction in other forums is permitted, provided the original author(s) or licensor are credited and that the original publication in this journal is cited, in accordance with accepted academic practice. No use, distribution or reproduction is permitted which does not comply with these terms.

Received: 27/10/2018 Accepted: 05/05/2020 